\title{
Direito à convivência familiar e comunitária: o Cadastro Nacional de Adoção sob a mira das lutas antirracistas ${ }^{1}$
}

\author{
Vanessa Cristina dos Santos Saraiva² \\ Carla Cristina Lima de Almeida ${ }^{3}$
}

\section{Resumo}

Este estudo realiza análise crítica e antirracista do Cadastro Nacional de Adoção. Consideramos que o cadastro reafirma práticas racializadas ao instrumentalizar o quesito raça/cor na "escolha" do filho de acordo com o ideal da branquitude. A análise bibliográfica dos dados evidencia que o racismo está posto, tendo em vista que crianças e adolescentes negros não são escolhidos nos processos de adoção. Nesse sentido, o direito à convivência familiar e comunitária desse público tem sido negado. Ações afirmativas nas políticas para crianças e adolescentes negros são uma forma de luta antirracista junto a esse segmento que tem suas vidas precocemente penalizadas.

\section{Palavras-chave}

Cadastro Nacional de Adoção; Ações afirmativas; Racismo contra crianças e adolescentes; Direitos; Política da Criança e do Adolescente.

The right to family and community coexistence: the National Adoption Register under the focus of anti-racist struggles

\begin{abstract}
This study aims to perform a critical and anti-racist analysis of the National Adoption Register. We assume that the register reaffirms racialized practices by operating the race/color question in the choice of the child according to the whiteness ideal. The bibliographic analysis of the data shows that racism is present, considering that black children and adolescents are not chosen in the adoption processes. In this sense, the right to family and community coexistence of this public has been denied. Black children and adolescents policies based on affirmative actions are a way of anti-racist struggles at this segment that have its lives early penalized.
\end{abstract}

\section{Keywords}

National Adoption Registry; Affirmative actions; Racism against children and adolescents; Rights; Child and Adolescent Policy.

Artigo recebido: novembro de 2020

Artigo aprovado: dezembro de 2020 


\section{Introdução}

O racismo e o preconceito contra crianças e adolescentes negros é tema pouco abordado ainda. Não poderíamos imaginar que uma prática tão cruel, discriminadora e separatória seria direcionada a um segmento que deveria ser protegido segundo as normativas internacionais e nacionais, como a Convenção dos Direitos da Criança (1989) e o Estatuto da Criança e do Adolescente (lei 8.069 de 1990).

Todavia, é preciso compreender que práticas racializadas estão institucionalizadas em diferentes espaços públicos e privados tal como Carmichael e Hamilton (1967) sinalizaram em seus estudos. Essas práticas, resultantes do racismo estrutural espinha dorsal das sociedades colonizadas, como é o caso brasileiro, têm colocado a população negra (conjunto de pretos e pardos) em situação de extrema vulnerabilidade, risco e morte social. O encarceramento em massa, a pobreza extrema, o diagnóstico de transtorno mental, o trabalho insalubre e perigoso e, no caso das crianças e adolescentes, o acolhimento e permanência em espaço institucional de forma massiva, são exemplos que explicitam a realidade vivenciada pela população negra.

Apesar disso, a sociedade brasileira tem produzido, ao longo do tempo, uma autoimagem de democracia racial que de fato nunca existiu, porém essa ideologia é responsável pela difıculdade de visualizar a racialização das relações sociais, criando resistências a ações que visem seu enfrentamento e superação.

No caso de crianças e adolescentes, as estratégias pactuadas na perspectiva de implementação de uma lógica de proteção foram a incorporação de determinações internacionais, as quais corroboraram para a materialidade da lei 8069 de 1990. Norma que concretiza um novo momento histórico denominado de Proteção Integral de crianças e adolescentes (RIZZINI e RIZZINI, 2004; LIMA 2018; SARAIVA, 2018), a qual constituiu uma rede interinstitucional de serviços que buscam sanar a situação de violências em que se encontram as crianças e adolescentes brasileiros. O sistema de garantia de direitos da criança e 
adolescente (SCDCA) estabelece serviços e permite atuação no horizonte da promoção, defesa e controle. Contudo, é preciso sinalizar que tais orientações e determinações regulamentadas se forjam em uma sociabilidade racializada e demarcada pelo sexismo, o que faz com que direitos de negros e de mulheres sejam negados a partir da agenda desumanizadora (ALMEIDA, 2014) vinculada ao sexo e à raça. Tais determinações sobre a realidade de pobres, negros, mulheres e crianças agravam o quadro de insegurança, iniquidades e desproteção social.

Portanto, neste artigo argumentamos que se de um lado tem-se a conquista de uma política de proteção às crianças e adolescentes considerados como sujeitos de direitos, por outro, a ausência do reconhecimento sobre como desigualdades raciais e de gênero, entrelaçadas com a classe, incidem sobre a realidade dessas crianças e adolescentes leva à manutenção do racismo em ações previstas por essa política, como é o caso do Cadastro Nacional de Adoção.

A adoção de crianças e adolescentes é considerada medida extrema que visa assegurar o direito à convivência familiar e comunitária. Entretanto, é notório o elevado número de crianças e adolescentes negros em instituições de acolhimento e, ao mesmo tempo, o perfil das crianças escolhidas, majoritariamente composto por crianças brancas e de pouca idade, evidenciando a incidência de relações racializadas nessa prática.

Verifica-se que, ao longo do tempo, algumas medidas foram utilizadas visando estimular adoções de crianças e adolescentes em situação de acolhimento institucional, a exemplo do Cadastro Nacional de Adoção. Neste artigo examinamos, sob a mira das ações afırmativas, em que medida esse dispositivo possibilita o acesso de crianças e adolescentes negros ao direito à convivência familiar e comunitária ${ }^{4}$.

Diante disso, problematizar as ações afırmativas como mecanismos construídos historicamente a partir da luta antirracista, assim como as formas como estas estão sendo compreendidas e incorporadas pelos operadores do SCDCA nas instituições que preconizam a proteção de 
crianças e adolescentes, se faz tarefa urgente e necessária. Isso porque é preciso analisar se as ações propostas no marco da doutrina de proteção integral têm revertido o quadro de iniquidades ou reafırmado o racismo, particularmente em se tratando de crianças e adolescentes em institucionalização. Nesse sentido, nos propomos a analisar o Cadastro Nacional de Adoção, sistema criado em 2008 com o objetivo de viabilizar adoções legais e assegurar a convivência familiar de crianças e adolescentes no Brasil, e verificar se esse tem atendido ao que se propôs ou tem se colocado como mecanismo que reafirma o racismo institucional.

\section{Ações afırmativas: desafios em uma realidade racista}

As ações afirmativas se constroem como mecanismo de enfrentamento de uma sociabilidade marcada pela violência institucionalizada e estigmatizadora direcionada a alguns grupos sociais. Compreendem a diferença como produtora e promotora de direitos. Assim, se colocam como desdobramento da igualdade formal e se apresentam como correspondência ao reconhecimento das diferentes posições que os sujeitos podem adquirir nas relações sociais em virtude da raça, etnia, sexualidade, orientação sexual, idade, gênero e outros demarcadores. As ações afirmativas estão focalizadas no binômio reconhecimento e distribuição (que devem estar reciprocamente unidos) a fim de romper com desigualdades / iniquidades sociais construídas historicamente por uma agenda de desumanização alçadas às categorias como a raça e o gênero, as quais afetam a vida dos sujeitos em diferentes territórios (PIOVESAN, 2005).

Essas vidas são atravessadas por intensa objetificação, desumanização, mercantilização e manipulação das subjetividades distintas aos padrões postos pela branquitude heteropatriarcal. Assim, aquelas subjetividades distintas do homem, branco, europeu são percebidas como inferiores, devendo sofrer sanções sociais como imobilidade social e econômica, pobreza multidimensional, sofrimento psíquico, violência física, aprisionamento, institucionalização. 
É diante desse quadro social desigual que a Convenção sobre todas as formas de discriminação racial é aprovada pelas Nações Unidades em 1965, tendo o Brasil como signatário em 1968. Nesse documento é veiculada a ideia de que "a superioridade baseada na diferença racial é postulada como falsa, moralmente condenável, socialmente injusta e perigosa (PIOVESAN, 2005, p. 6)", reafirmando que preconceito e discriminação racial se colocam como uma violação de direitos humanos passível de penalização.

É um documento que reconhece ainda a existência do racismo no Brasil e rompe com as práticas negacionistas ao preconizar que sejam adotados mecanismos que desconstruam as desigualdades postas pelo racismo, sexismo e qualquer outra forma de hierarquização social. Assim, as ações afırmativas defınidas como medidas temporárias postas pelo Estado com o objetivo de combater iniquidades e desigualdades sociais junto aos sujeitos racializados e generificados passam a ser colocadas na realidade social brasileira. Auxílios, bolsas, políticas públicas, cotas, fomento a pesquisas são alguns exemplos das ações afirmativas no Brasil.

A década de 1990 é marcada pelo tensionamento do movimento negro e a implementação do Programa de Superação do Racismo e da Desigualdade Racial. Nos anos 2000 a Política Nacional de Igualdade Racial é regulamentada através do decreto 4886 de 2003 . Todas as iniciativas objetivam reduzir desigualdades, promover a igualdade racial direcionada à população negra brasileira a partir de ações estatais. Ou seja, fazer com que as ações afırmativas se desloquem do campo formal, tendo aplicabilidade na realidade social. Salvador (2020, p.212) chama atenção para o fato de que "[...] a política afırmativa é, geralmente, reconhecida como um instrumento político voltado para inclusão de grupos subordinados ou subalternizados, muito embora seu campo de intervenção seja muito maior".

No caso de crianças e adolescentes, o artigo 197 incluído pela lei 13.509 de 2017 trata do estímulo à adoção interracial, de crianças 
com deficiência e ou doenças crônicas, inscrevendo-se no debate das ações afirmativas conforme vimos tratando. Em alguns estados brasileiros programas como a guarda subsidiada que oferta recursos financeiros às famílias que se candidatem à adoção estão em curso, como é o caso do Paraná. No Rio de Janeiro o programa "Um lar pra mim", regulamentado pela lei estadual 3.499/2000, postula a destinação de recursos financeiros aos servidores do estado que adotem crianças que estejam disponíveis para a adoção. Juntas, essas iniciativas que readéquam o ECA, assim como as ações coordenadas pelos estados podem ser consideradas como ações afirmativas, tendo em vista que vislumbram mudanças no quadro social de crianças e adolescentes brasileiros de segmentos sociais que aguardam por anos em instituições de acolhimento.

Mas, mesmo diante destas propostas as ações afırmativas são constantemente tensionadas a partir de uma compreensão errônea de que há privilégio na desigualdade. Nesse sentido, além da população negra enfrentar cotidianamente as duras condições de vida impostas pelo racismo estrutural e institucional, verifıcamos que as ações afırmativas estão tensionadas, inseridas em um campo de disputas societárias, de discurso, de valores sociais e por isso enfrentam tantos questionamentos. Além disso, existir ações afırmativas no Brasil signifıca assumir o racismo estrutural, o estado de privilégios da branquitude e a desigualdade social marcada pelo racismo e sexismo.

Nesse sentido, é preciso situar o lugar do negro na sociedade brasileira: o encarceramento em massa, os altos índices de homicídios, de transtornos mentais e suicídios, de pobreza e, no caso das crianças, o lugar de acolhimento e não adoção nos mostra que a população negra está em um não lugar, no lugar da desproteção social, em um lugar de sofrimento com a histórica desigualdade (CONZALEZ e HASENBALG, 1982).

É nessa realidade onde a representatividade (ocupação de sujeitos negros em espaços de decisão e poder) impacta na elaboração, avaliação e monitoramento das leis, positiva ou negativamente, que 
- Cadastro Nacional de Adoção se materializa. A proposta, datada de 2008 objetivava acelerar processos adotivos a partir da reunião de informações sobre candidatos e crianças e adolescentes adotáveis. E pensando na realidade do acolhimento institucional no Brasil, poderia ser examinado na perspectiva da ação afırmativa, haja vista que majoritariamente e historicamente crianças e adolescentes negros constituem o principal grupo dos que são abrigados ${ }^{5}$ (CNJ, 2020).

Contudo, a ficha cadastral a ser preenchida pelos candidatos contendo o quesito opção raça/cor como uma das opções remonta o período colonial, onde sujeitos escravizados eram escolhidos ou não a partir de suas habilidades, condições físicas e aparência. Mas por que essa analogia? Porque as crianças e adolescentes negros não são elegíveis, não são percebidos como futuros filhos, vistos como aqueles que não precisam de proteção já que possuem fenótipo que está em desacordo com o padrão de beleza e moralidade imposto socialmente: o branco.

O pressuposto consiste no fato de que somente a existência da opção raça/cor no cadastro, não relacionada com a realidade das instituições de acolhimento, com as relações sociais racistas e sexistas, se coloca como reafirmação do racismo e perpetuação da desigualdade. Escolher um filho a partir das características físicas e fenotípicas não é possível para os pais biológicos, então, por que existir essa opção no cadastro para candidatos à adoção? A explicação só poderia ocorrer numa sociedade em que a "cor da pele"7 faz diferença e organiza estruturalmente e hierarquicamente as relações sociais.

\section{Cadastro Nacional de Adoção e o quesito raça/cor}

No ano de 2008, o Conselho Nacional de Justiça (CNJ), construiu um banco nacional com dados referentes às Crianças e Adolescentes e os candidatos habilitados à adoção com o objetivo de acelerar e viabilizar o processo de adoção legal no Brasil. O Cadastro Nacional de Adoção, hoje Sistema Nacional de Adoção e Acolhimento ${ }^{8}$, é mecanismo que busca romper com as determinações que inviabilizam o 
processo adotivo: a burocracia e a morosidade da justiça são alguns exemplos. Vale ressaltar que atualmente temos 30.902 mil crianças acolhidas, as quais aguardam que o direito à convivência familiar e comunitária seja assegurado.

É preciso situar ao leitor sobre o cumprimento de determinação contida no ECA com a criação do cadastro/ banco de dados nacional postulada desde 1990. Considerando o "Art. 50: A autoridade judiciária manterá, em cada comarca ou foro regional, um registro de crianças e adolescentes em condições de serem adotados e outro de pessoas interessadas na adoção (BRASIL, 1990; 2010)." O objetivo, além de acelerar processos adotivos, é prioritariamente, obter uma organização da história de vida de crianças e adolescentes, cumprir o ECA no que diz respeito ao tempo de permanência em espaços institucionais (não podendo ser superior a 2 anos) e assegurar direitos fundamentais: vida, saúde, crescimento em ambiente protegido.

É preciso considerar ainda que adoção, em outros termos, a inserção de crianças e adolescentes em famílias substitutas, é a última medida protetiva imposta a toda criança e adolescente que tenha direitos violados, dentre eles o de convivência familiar e comunitária. Antes disso, diálogo com famílias, penalizações verbais e escritas, encaminhamentos à rede intersetorial de atendimento com vistas a manter as crianças e adolescentes em proximidade com a família biológica devem ser realizados com mediação dos conselhos tutelares (BRASIL, 1990).

Não obtendo sucesso nesse acompanhamento territorializado e personalizado (respeitando as particularidades de cada grupo familiar), a medida de acolhimento institucional é aplicada e posteriormente, após trabalho de equipe de unidades de acolhimento, a adoção (nacional e internacional) pode ser viabilizada caso a reintegração familiar não seja possível. Assim, a adoção é mecanismo que busca viabilizar famílias substitutas para as crianças e adolescentes de forma indistinta. Ou seja, o direito é para todas as crianças e adolescentes independente de raça, gênero, sexualidade. 
No entanto, é preciso ressaltar que mesmo diante do fato de a medida ser de caráter indistinto, os dados do Cadastro Nacional de Adoção evidenciam que majoritariamente os abrigos são compostos por crianças negras (pretas e pardas segundo nomenclatura do IBCE). Somente no Estado do Rio de Janeiro, considerando os dados produzidos pelo Módulo Criança Adolescente de 2020, 85\% aproximadamente das crianças acoIhidas aguardando processo adotivo ou reintegração familiar são negras. Os dados nacionais mostram ainda que existem candidatos 13,99\% que somente aceitam crianças de raça branca, ao passo que $0,78 \%$ somente aceitam crianças da raça negra. 61,65\% não aceitam adotar grupos de irmãos; 26,61\% desejam adotar somente crianças do sexo feminino e 8,19\% desejam adotar somente crianças do sexo masculino (CNJ, 2020). De tudo, observamos demarcadores raciais, de idade e gênero tensionando lugares sociais das crianças que deveriam ser protegidas indistintamente.

O quesito raça/cor ${ }^{9}$ mecanismo que permite a contabilização de sujeitos negros em espaços institucionais e que deveria ser utilizado para construir estatísticas que busquem romper com as iniquidades sociais, assim como fomentar a construção de ações afırmativas, está sendo utilizado como mecanismo de reatualização e recolocação do racismo brasileiro. Isso porque, o quesito posto em ficha cadastral a ser preenchida pelos candidatos à adoção, sem qualquer problematização ou articulação com a questão racial brasileira reforça práticas racistas. É preciso problematizar sobre pigmentocracia ${ }^{10}$, sobre fenótipos e sobre quem é negro no Brasil. Isso requer esforço, mas também posicionamento antirracista no horizonte da garantia de direitos.

A "escolha"11 do filho ideal branco, sexo feminino e com menos de 3 anos de idade segundo Vargas (1998), Espíndola (2019) e Barros (2014) deve ser combatida, considerando-se a realidade existente nos abrigos: crianças negras, grupos de irmãos, maiores de 3 anos de idade. Outro aspecto é o fato de que um filho não pode ser escolhido a partir das necessidades de adultos, mas sim, a referência deve ser a priorização de uma família para uma criança. (BRASIL, 1990; BITTENCOURT, 2008). 
Racismo institucional contra crianças: é possível romper com essa lógica?

O racismo pode ser definido como um conjunto de práticas e valores construído historicamente com a capacidade de atingir materialmente, subjetivamente e simbolicamente um grupo racial a partir das ideias de hierarquia, poder e racialidade superior. No Brasil, país herdeiro do escravismo e da colonização, esses aspectos se concentraram na relação entre brancos versus negros, tendo a branquitude como padrão de ser humano a ser seguido no campo político, social, estético e cultural a partir de uma idealização construída pelo racismo científico de que brancos são mais inteligentes, fortes, bonitos (MUNANCA, 2003).

A branquitude passa ser significado de vários aspectos da vida social, precisando constituir pactos narcísicos, segundo Bento (2002), a fim de manter o poder sobre os demais sujeitos mesmo após o "término" do escravismo. É assim, que leis, normativas e o modo de ser pautado nos valores da branquitude são construídos e reafirmados como os únicos valores humanitários e sociais em detrimento de qualquer outra forma de ser e viver construída por outros sujeitos como os africanos, ameríndios e asiáticos (SCHUCMAN, 2012).

É a partir dessa realidade racializada e também sexista, onde o gênero é colonizado (LUGONES, 2020) que o racismo nos espaços institucionais se coloca como desdobramento do racismo estrutural que forjou a sociabilidade brasileira. Hamilton e Carmicael (1967) militantes do movimento negro estadunidense que forjaram o termo racismo institucional afirmam que se trata de falha estatal programada na execução de serviços destinados à população negra. Ou seja, é perpetuação do racismo de forma diferenciada daquela que ocorria no período colonial que almeja manter subalternização, imobilização social e institucionalizar uma política de morte centrada na figura da população negra: homens, mulheres e crianças.

Lole e Almeida (2017) tratam das práticas sexistas institucionais alinhadas ao fenômeno da feminização da pobreza como produto de 
uma sociabilidade eurocentrada, racista, sexista e capitalista. E isso, impacta diretamente na formação e funcionamento das famílias, majoritariamente chefiadas por mulheres não brancas. Essas famílias e essas mulheres devem se enquadrar ao padrão social imposto à muIher a partir de uma divisão sexual e racial do trabalho desigual: cuidadora, mãe, esposa e trabalhadora (LUGONES, 2020).

Práticas sexistas empurram uma responsabilização do cuidado às mulheres, assim como criminalização quando estas mulheres não conseguem exercer o cuidado a que foram historicamente destinadas. Gueiros (2007) afirma que ocorre um movimento de desenraizamento social das famílias e um fomento de práticas adotivas. Motta (2008) salienta a dinâmica de entrega ao filho em adoção, assim como a criminalização, penalização, julgamento e moralização das condições que conduziram essas mulheres a decidirem pela entrega. Saraiva (2020) ressalta que a estratégia incorporada por muitas famílias negras diante das dificuldades de estabelecer cuidados com os filhos é o cuidado coletivo, a circulação de crianças, a qual também é criminalizada pelo sistema de justiça brasileiro.

Nesse sentido, a situação de mulheres responsáveis pelas crianças nos diferentes exercícios de maternagem transferida (COSTA, 2002), se torna complexa e o cuidado se torna cada vez mais comprometido, por não atingir o padrão imposto socialmente e institucionalmente, sobretudo, pelos órgãos e instituições que compõem o SCDCA. Em contrapartida, verificamos um processo massivo de institucionalização de crianças e adolescentes, situação que, de fato, rompe com a proposta contida no ECA, remonta à era do menorismo brasileiro ${ }^{12}$, onde crianças e adolescentes eram institucionalizados sob o viés da proteção, porém por estarem em situação irregular.

Concretamente, temos ciclos ininterruptos que penalizam mulheres e crianças, sobretudo, empobrecidas, negras e moradoras de favelas por todo o Brasil. Esse é demarcado pela culpabilização da mulher, acolhimento, institucionalização e não adoção. No que diz respeito a 
esse ciclo verificamos as marcas do racismo institucional, já que são mulheres negras que têm seus filhos acolhidos e as crianças negras que permanecem institucionalizadas nos abrigos do país cuja situação é: agonizando devidos os parcos investimentos e mediatizados por viés religioso, ferindo o direito à liberdade religiosa das crianças e adolescentes (LIMA, 2015; SARAIVA, 2019). O ECA em seu artigo 197 preconiza o incentivo à adoção interracial, contudo, a escolha por essas crianças e adolescentes é demarcada pelo racismo.

$\$ 1^{\circ}$ É obrigatória a participação dos postulantes em programa oferecido pela Justiça da Infância e da Juventude, preferencialmente com apoio dos técnicos responsáveis pela execução da política municipal de garantia do direito à convivência familiar e dos grupos de apoio à adoção devidamente habilitados perante a Justiça da Infância e da Juventude, que inclua preparação psicológica, orientação e estímulo à adoção inter-racial, de crianças ou de adolescentes com deficiência, com doenças crônicas ou com necessidades específicas de saúde, e de grupos de irmãos (BRASIL, 2017).

Isso é reforçado quando opções são postas (como na ficha do perfil de crianças no cadastro nacional de adoção), a realidade não é problematizada e o racismo não é discutido. Crianças e adolescentes negros não são percebidos como adotáveis. As preferências são construídas nessa realidade onde existe um padrão ideal de sujeito (o branco). A realidade brasileira evidencia que majoritariamente os sujeitos negros representam 54\% da população (BRASIL, 1990; VARCAS, 1998; SCHUCMAM, 2012)

Assim, é preciso pensar em alternativas que modifiquem tal realidade. Isso porque o quesito raça/ cor que deveria auxiliar a produzir dados que descontruam essa sociabilidade desigual, está reafirmando o racismo (ESPÍNDOLA, 2019). A ausência de consciência racial e do não entrecruzamento do perfil das crianças disponíveis, a ideia de um país mestiço e harmônico, preconceito e racismo que desumaniza os sujeitos, repõe ciclos, repõe pauperismo, repõe acolhimento 
e não adoção fazendo com que o racismo seja revelado e ao mesmo tempo escondido (MUNANGA,2003).

Diante disso propomos que algumas medidas sejam adotadas no sentido de garantia de humanização de crianças e adolescentes. A capacitação continuada, o questionamento sobre o lugar da branquitude na luta antirracista, a produção de conhecimento, o exercício profissional cotidiano a partir de uma postura antirracista. E por fim no caso de profissionais que atuem com os temas acolhimento, adoção, racismo é preciso consciência crítica racial e sensibilidade/ responsabilização para expor essa realidade, sobretudo, aos candidatos a adoção, somente assim, poderemos pensar na garantia efetiva do direito a convivência familiar e comunitária, ao desenvolvimento sadio em família, na vida de nossas crianças e adolescentes negros.

Hooks (2013) nos deixa uma lição importante na obra "Ensinando a transgredir" ao pensar a prática pedagógica como transformadora e libertadora de uma sociabilidade racializada e generifıcada. Acreditamos que uma atuação profissional assentada nessas práticas que se alçam a uma crítica antirracista e antissexista dessa realidade social no espaço de SCDCA se coloca como ação basilar para mudanças importantes nos espaços institucionais. É somente a partir desse reordenamento que poderemos repensar o cadastro nacional de adoção, sua funcionalidade e utilidade para a luta antirracista no que diz respeito as nossas crianças e adolescentes negros.

\section{Considerações Finais}

A História tem nos demonstrado que somente a existência das ações afırmativas não é garantia de que mudanças significativas sejam observadas na vida dos sujeitos contemplados. Isso porque é preciso que as ações afirmativas, a consciência da existência da desigualdade e a consciência crítica estejam interconectadas. Caso contrário, estaremos recolocando o racismo, em outros termos, práticas violadoras e desumanizadoras dos sujeitos na ordem do dia. 
Alguns exemplos foram evidenciados nesse estudo, como o uso indevido do quesito raça/ cor postulado no Cadastro Nacional de Adoção onde ao invés de produzir dados que combatam as iniquidades sociais postas no acolhimento, passam a ser utilizados como demarcadores de crianças e adolescentes indesejáveis, não adotáveis.

Diante dessa condição (in)comum nos espaços institucionais somente o discurso antirracista não se consolida como parâmetro de modificação da realidade social das famílias e crianças e adolescentes acolhidos, aguardando a tomada de decisão de "especialistas" (DONZELOT, 1980) nesses espaços de poder tão distantes da realidade desigual em que foram sociabilizados. É preciso mais: capacitação continuada antirracista, questionamento dos privilégios, alteridade, construção de uma consciência e pedagogia profissional antirracista.

O uso dos espaços de habilitação destinados aos candidatos à adoção pode e deve ser considerado espaço de privilégio. Isso porque permite um processo de desconstrução do racismo. Ponderar com essas famílias a partir da afetividade é estratégia interessante e que pode tensionar positivamente o processo de "escolha" por um filho. Um filho real, não idealizado, que possui irmãos, que possui uma história de vida e que pode sim ser negro.

Diante disso, é preciso pensar em estratégias que rompam com essa realidade racializada que imobiliza e institucionaliza nossas crianças e adolescentes. É preciso pensar em avaliação e monitoramento das políticas públicas, no caso, a proposta contida no cadastro, no sentido de evidenciar pontos positivos ou não. A partir disso podemos pensar em novos processos de habilitação de candidatos, em dimensão pedagógica dos profissionais que executam esses cursos, na construção coletiva de consciência antirracista e antissexista, e na radical mudança de vida de nossas crianças e adolescentes por meio da viabilização dos direitos fundamentais desse segmento, dentre eles o direito à convivência familiar e comunitária. 
Consideramos a ideia que ações afırmativas no âmbito das políticas que afetam crianças e adolescentes negros no Brasil, particularmente no campo das práticas de adoção, sejam uma forma de luta antirracista urgente junto a esse segmento social e racial que tem suas vidas precocemente penalizadas.

\section{Referências}

ALMEIDA, Magali da S. Desumanização da população negra: genocídio como princípio tácito. Em Pauta, n. 34, v. 12, p. 131- 154, $2^{\circ}$ semestre 2014.

BENTO, Maria Aparecida da Silva. Pactos narcísicos: branquitude e poder nas organizações empresariais e no pode público. Tese (Doutorado) - Programa de Pós-graduação em Psicologia Escolar e do Desenvolvimento Humano do Instituto de Psicologia, Universidade de São Paulo, 2002.

BRASIL. Estatuto da Criança e do adolescente. Brasília, 1990.

BRASIL. Lei 12.010, de 2009. Disponível em: http://www.planalto.gov.br/ccivil_03/_Ato2007-2010/2009/Lei/L12010.htm. Acesso em 20 jun. 2020.

BRASIL. Lei 13.509, de 2017. Disponível em: http://www.planalto.gov.br/ccivil_03/_ato2015-2018/2017/lei/l13509.htm. Acesso em 20 jun. 2020.

BARROS, Rosana Maria de. Adoção e Família: a preferência pela faixa etária certezas e incertezas. Curitiba: Juruá, 2014.

BITTENCOURT, Sávio. Manual do pai adotivo. Niterói: Nota Bene, 2008.

CARMICHAEL, Stokely e HAMILTON, Charles. Black Power: the political of liberation in America. Disponivel em: https://mygaryislike.files.wordpress. com/2016/12/black-power-kwame-ture-and-charles-hamilton.pdf. Acesso em 09 de março. 2020.

COSTA. Suely Gomes. Proteção social, maternidade transferida e lutas pela saúde reprodutiva. Disponivel em: https://www.scielo.br/pdf/ref/ v10n2/14959.pdf. Acesso em 29 mai. 2020.

CNJ. Relatório de pretendentes cadastrados (nacional). Disponível em: https:// www.cnj.jus.br/cnanovo/pages/publico/index.jsf. Acesso em 02 nov. 2020.

ESPÍNDOLA. Sandro Pitthan. Filho, qual é a sua raça? racismo institucional através do Cadastro Nacional de Adoção. Disponivel em: https://www. arca.fiocruz.br/bitstream/icict/35089/2/ve_Sandro_Pitthan_ENSP_2019. Acesso em 20 jun. 2020. 
DONZELOT, Jacques. A polícia das famílias. Rio de Janeiro: Graal, 1980.

DOUCLAS, Mary. Pureza e perigo: ensaio sobre a noção de poluição e tabu. Lisboa: Edições 70, s.d. (trad. por Sônia Pereira da Silva, 1966).

GUEIROS. Dalva Azevedo Gueiros. Adoção consentida: do desenraizamento da família à prática de adoção aberta. São Paulo: Cortez, 2007.

CONZALEZ, Lélia e HASENBALG, Carlos. Lugar de negro. Rio de Janeiro: Marco Zero, 1982.

HOOKS, bell. Ensinando a transgredir: a educação como prática da liberdade. Tradução de Marcelo Brandão Cipolla. São Paulo: Editora Martins Fontes, 2013.

LOLE, Ana; Lima de ALMEIDA, Carla Cristina. Políticas para mulheres e lutas feministas: os paradoxos da proteção social. Argumentum, v. 9, n. 1, p. 46-60, jan-abril, 2017.

LIMA, Rodrigo Silva (2015). O mistério do orçamento dos abrigos no Rio de Janeiro. Textos \& Contextos (Porto Alegre), 14(1), 186 - 201. https://doi. org/10.15448/1677-9509.2015.1.20095.

LUGONES, María. Colonialidade e gênero. Disponível em: https://bazardotempo.com.br/colonialidade-e-genero-por-maria-lugones-2/. Acesso em 20 de jan. 2020.

MINISTÉRIO DA SAÚDE. Guia de Implementação do Quesito Raça/ Cor/Etnia. Disponível Em: http://bvsms.saude.gov.br/bvs/publicacoes/guia_implementacao_raca_cor_etnia.pdf. Acesso em 30 out. 2020.

MOTTA, Maria Antonieta Pisano. Mães abandonadas: a entrega de um filho em adoção. São Paulo: Cortez, 2008.

MUNANGA, Kabengele. Uma abordagem conceitual das noções de raça, racismo, identidade e etnia. Disponivel em: https://www.geledes.org.br/ wp-content/uploads/2014/04/Uma-abordagem-conceitual-das-nocoes-de-raca-racismo-dentidade-e-etnia.pdf. Acesso em 20 de jan. 2020.

PIOVESAN, Flávia. Ações afirmativas da perspectiva dos direitos humanos. Cadernos de Pesquisa, v. 35, n. 124, jan./abr. 2005.

RIO DE JANEIRO. Lei 3499, de 2000. Disponível em: https://gov-rj.jusbrasil. com.br/legislacao/136943/lei-3499-00. Acesso em 28 out. 2020.

SALVADOR, Andréia Clapp. O papel protagonista do Pré-Vestibular para Negros e Carentes (PVNC) nas políticas afırmativas - a experiência da educação superior brasileira. Em Pauta, n. 45, v. 18, p. 211-223, $1^{\circ}$ Semestre de 2020. 
VARGAS, Marlizete Maldonado. Adoção tardia: da família sonhada à família possível. São Paulo: Casa do Psicólogo, 1998.

RIZZINI, Irene e RIZZINI, Irma. A institucionalização de crianças no brasil: percurso histórico e desafios do presente. Disponivel em: http://acolhimentoemrede.org.br/site/wp-content/uploads/2015/04/ebook_institucionalizacao_de_criancas_no_brasil.pdf. Acesso em 02 de nov. 2020.

SARAIVA, Vanessa Cristina dos Santos. Intolerância religiosa contra as crianças e adolescentes na Baixada Fluminense: resistindo nos abrigos de Duque de Caxias. Disponivel em: file:///C:/Users/Vanessa\%20Saraiva/ Downloads/723-1-1371-1-10-20190626\%20(1).pdf. Acesso em 30 out. 2020.

SARAIVA, Vanessa Cristina dos Santos. Repensando a adoção e a circulação de crianças na familia brasileira. Disponível em: https://www.e-publicacoes.uerj. br/index.php/revistaempauta/article/view/47216. Acesso em 30 out. 2020.

SARAIVA, Vanessa Cristina dos Santos. Reflexões sobre a medida de acolhimento institucional e o direito de convivência familiar em Duque de Caxias. TCC (Graduação - Especialização em Políticas Sociais e Intersetorialidade) Instituto Nacional de Saúde da Mulher, da Criança e do Adolescente Fernandes Figueira. Rio de janeiro, 2018.

SCHUCMAN, Lia Vainer. Famílias inter-raciais: tensões entre cor e amor [online]. Salvador: EDUFBA, 2018.

UNICEF. Convenção sobre os direitos da criança. Disponivel em: https://www.unicef.org/brazil/convencao-sobre-os-direitos-da-crianca. Acesso em 30 out. 2020.

\section{Notas}

1 Este artigo é produto das reflexões realizadas no decorrer do processo de doutorado desenvolvido na UERJ onde a aluna têm discutido interseccionalmente racismo, infância e adolescência, acolhimento e adoção. A aluna é orientada pela Dr ${ }^{a}$ Carla Cristina Lima de Almeida. Este trabalho é apoiado pela CAPES.

2 Assistente Social. Especialista em Políticas Públicas e Intersetorialidade (IFF-FIOCRUZ). Mestre em Serviço Social (UFRJ). Doutoranda Universidade do Estado do Rio de Janeiro. Pesquisadora do NUDISS UFF. Brasil. Orcid https://orcid. org/0000-0002-9515-7910. Email: vancristinasaraiva@gmail.com

3 Assistente Social. Doutora em Ciências Sociais (IFCH/UNICAMP). Pós-doutora no Núcleo de Estudos em Gênero PAGU (UNICAMP). Professora Associada da Faculdade de Serviço Social da UERJ. Coordenadora do Núcleo de Estudos Família e Gênero da FSS/UERJ. Professora do PPCSS/UERJ. Brasil. Orcid https://orcid. org/0000-0002-8828-4997. E-mail: carlacristina.almeida@yahoo.com.br 
4 Não estamos aqui defendendo que crianças e adolescentes negros devam ser adotados, pois reconhecemos a necessidade de assegurar que as famílias negras tenham o direito de cuidar de seus filhos. Porém, na condição de rupturas e destituição do poder familiar cabe pensar como garantir que essas crianças e adolescentes encontrem condições de convívio social e familiar protegido.

5 Ver mais em Rizzini e Rizzini (2004); Saraiva (2018).

6 É necessário observar que os padrões estéticos estão profundamente conectados com padrões morais e uma vez associados produzem muitas justificativas para iniquidades sociais e raciais. Mary Douglas (1966) é uma autora que apresenta em importante estudo a articulação entre ideias sobre pureza e noções de perigo, mostrando conexões entre estética e moralidade.

7 O termo "raça" é bem mais amplo do que "cor de pele", pois denota um conjunto de relações sociais racializadas que atravessam a classificação dos corpos em virtude de sua raça/cor, mas não se detém nela articulando elementos como nacionalidade, cultura, história e outras relações de poder. Cf. Munanga (2003).

8 No ano de 2019 ocorreu um reordenamento dos cadastros e assim, após unificação do cadastro nacional de adoção com o cadastro de crianças acolhidas, cria-se o Sistema Nacional de Adoção brasileiro.

9 A portaria $\mathrm{n}^{\circ}$ 344, de 01 de fevereiro de 2017 do Ministério da Saúde (MS), que dispõe sobre o preenchimento do quesito raça/cor nos formulários dos sistemas de informação em saúde, bem como a Portaria n 201, de 03 de outubro de 2014, que regulamenta a coleta do quesito raça/cor/etnia nos formulários e sistemas de informação da Secretaria de Estado da Saúde do Distrito Federal e dá outras providências regulamentam o uso do quesito na perspectiva de construir estatísticas e políticas públicas que combatam iniquidades sociais, construir dados em saúde sobre população negra e mapear esse segmento.

10 Cf Alice Walker no ensaio "If the Present Looks Like the Past, What Does the Future Look Like?", que foi publicado no livro "In Search of Our Mothers' Garden" em 1982.

11 O termo encontra-se entre aspas por não concordarmos que as características físicas de um filho são escolhidas. O termo remonta à objetificação, ao adultocentrismo, aos desejos e anseios de adultos, ainda que muitas vezes o aspecto físico seja levantado como forma de facilitar a construção dos vínculos familiares. Esse argumento, no entanto, evidencia a dificuldade de se lidar com a diversidade.

12 Período em que a política pública direcionada à infância brasileira era pautada na Doutrina da Situação Irregular, tendo os códigos de menores de 1927 e 1979 como leis que respaldavam as ações. 